\title{
Incorporation of 5-Methylorcylaldehyde and Methionine into the Acetogenin (Polyketide) Gliorosein in Gliocladium roseum
} I.M.I. 93065

\author{
By M. W. STEWARD AND N. M. PACKTER \\ Department of Biochemistry, University of Leeds
}

(Received 15 December 1967)

\begin{abstract}
1. methyl-14C-labelled 1,3-dihydroxy-4,5-dimethylbenzene, 5-methylorcylaldehyde and 5-methylorsellinic acid were synthesized from orcinol and sodium $\left[{ }^{14} \mathrm{C}\right]$ cyanide and tested for activity as precursors of gliorosein. ring- ${ }^{14} \mathrm{C}$-labelled orcylaldehyde was also prepared. $5\left[{ }^{14} \mathrm{C}\right]$-Methylorcylaldehyde was incorporated into gliorosein ( $36 \%$ conversion); all the radioactivity was located in the $C$-methyl groups. 5-Methylorsellinic acid was decarboxylated by Gliocladium roseum and the resulting phenol was secreted into the medium. 2. The formation of an enzymebound derivative of 5-methylorsellinic acid as the first aromatic compound in the biosynthesis of gliorosein is suggested to explain these results. 3. ring- ${ }^{14} \mathrm{C}$-labelled 3,4-dihydroxy-6-methyltoluquinone was also effectively incorporated into gliorosein and related products $\left(20 \%\right.$ conversion). 4. Sodium $\left[{ }^{14} \mathrm{C}\right]$ formate and $\left[\mathrm{Me}^{-14} \mathrm{C}\right]$ methionine were incorporated into gliorosein and related products (15.4 and $22.2 \%$ conversion respectively). Isolation and estimation of the radioactivity in the $O$-methyl and $C$-methyl groups in the ${ }^{14} \mathrm{C}$-labelled gliorosein thus formed showed an appreciable difference in the specific activities of the two types of methyl group (14 and $15 \%$ respectively). The results in the doubly-labelled methionine experiment indicate that the $C$-methyl group arises in the same manner as that in ergosterol; one of the original hydrogen atoms of the methyl group is lost. This confirms that $C$-methylation occurs at an ethylenic group at the aliphatic level. 5. The sequence of reactions at the aromatic level leading to the formation of gliorosein is proposed as 5-methylorsellinyl-enzyme $\rightarrow$ 3-hydroxy-5-methylorsellinyl-enzyme $\rightarrow$ 3,4 - dihydroxy - 6 - methyltoluquinol $\rightarrow 3,4$ - dimethoxy - 6 - methyltoluquinol $\rightarrow$ gliorosein.
\end{abstract}

It has been established that gliorosein $(1,6$ dihydro-3,4-dimethoxy-6-methyltoluquinone; $I$ ) is derived via the 'acetate-plus-malonate' pathway of acetogenin biosynthesis (Bentley \& Lavate, 1965; Packter \& Steward, 1967). Birch, Fryer \& Smith $(1958 b)$ have also shown that sodium $\left[{ }^{14} \mathrm{C}\right]$ formate is incorporated ( $5 \%$ conversion) into the $O$-methyl groups and one of the $C$-methyl groups of aurantiogliocladin (3,4-dimethoxy-6-methyltoluquinone). This substance is produced from gliorosein by oxidation in the medium (Steward \& Packter, 1965). The other $C$-methyl group is derived from acetate (Birch et al. 1958b; Bentley \& Lavate, 1965). The specific activity of the $O$-methyl groups was somewhat higher $(10 \%)$ than that of the $C$-methyl group. Further, Birch, Cameron, Holloway \& Rickards (1960) have shown that the $O$-methyl group of novobiocin, produced by Streptomyces niveus, is labelled to a greater extent than the $C$-methyl group of the gem-dimethyl group attached to the noviose ring $(35: 31)$ when the organism is incubated with $\left[M e^{-14} \mathrm{C}\right]$ methionine. Birch et al. $(1958 b ; 1960)$ did not comment on these differences.

$O$-Methylation may occur via a transmethylation reaction involving $S$-adenosylmethionine in which the methyl group is transferred intact (Greenberg, 1963). It has been suggested that $C$-methylation during the synthesis of cyclopropane acids and tuberculostearic acid (10-methylstearic acid) may occur via a derivative possessing a group such as $\mathrm{CH}_{2}=\mathrm{S}<$ in which a proton has been lost from the methyl group of $S$-adenosylmethionine to give an ylide (Pohl, Law \& Ryhage, 1963; Lederer, 1964). This derivative could then transfer a methylene unit by addition to an ethylenic double bond and the methylation would be completed by a reduction step. Alternatively a double bond may be methylated directly, as in ergosterol biosynthesis from lanosterol. A proton (from the original methyl

Bioch. 1968, 109 
<smiles>COC1=C(OC)C(=O)[C@@](C)(C(C)C)[C@@H](C)C1=O</smiles>

(I)<smiles>[R]c1c(O)cc(O)c(C)c1C</smiles>

(II) $\mathbf{R}=\mathbf{H}$

(III) $\mathrm{R}=\mathrm{CHO}$

(IV) $\mathrm{R}=\mathrm{CO}_{2} \mathrm{H}$<smiles>CC1=C(C)C(=O)C(O)=C(O)C1=O</smiles>

(V) group) is subsequently lost to give a methylene derivative (Akhtar, Hunt \& Parvez, 1967).

Another mechanism for the formation of a $C$-methyl group, from a different $\mathrm{C}_{1}$ pool, however, is utilized in the biosynthesis of thymidylic acid. In Escherichia coli, a methylene unit from $N^{5} N^{10}$. methylenetetrahydrofolate is transferred to the pyrimidine ring of $2^{\prime}$-deoxyuridylic acid (Wahba \& Friedkin, 1962; Pastore \& Friedkin, 1962). Dihydrofolate is also formed in this reaction.

Accordingly, it was decided to investigate whether $\left[\mathrm{Me}-{ }^{14} \mathrm{C}\right]$ methionine or $\left[{ }^{14} \mathrm{C}\right]$ formate was the primary precursor of the additional $C$-methyl group of gliorosein. Also, in view of the apparent difference in the labelling of the $O$-methyl and $C$-methyl groups found by Birch et al. (1958b), studies on the relative labelling of these groups in gliorosein from $\left[\mathrm{Me}^{-{ }^{14} \mathrm{C}}\right]$ methionine and $\left.{ }^{14} \mathrm{C}\right]$ formate were carried out.

Recent work in this Laboratory has indicated that 6-methylsalicylic acid and orsellinic acid are not precursors of gliorosein. These results suggest that 5-methylorsellinic acid (2,4-dihydroxy-5,6dimethylbenzoic acid; IV) may be the first aromatic intermediate formed (Packter \& Steward, 1967). This substance was therefore prepared, specifically ${ }^{14} \mathrm{C}$-labelled at one of the methyl groups, and tested for activity as a precursor of gliorosein in Gliocladium roseum. The related aldehyde (III) and phenol (II) were also synthesized and tested. Preliminary results on some of this work have already been reported (Steward \& Packter, 1967).

\section{METHODS}

Isolation of metabolites. G. roseum (I.M.I. 93065) was obtained from the Commonwealth Mycological Institute (Kew, Surrey). It was incubated with Raulin-Thom medium (Anslow \& Raistrick, 1938) as surface (stationary) cultures at $24-25^{\circ}$. Gliorosein and related products were isolated from the medium and resolved from each other by column chromatography on silicic acid-Celite (Packter \& Steward, 1967). Gliorosein was initially purified by rechromatography followed by crystallization from light petroleum to constant specific activity and melting point. It was further purified in the degradation experiments by conversion into the quinone. (Quinone, quinol and quin- hydrone refer throughout to the appropriate derivatives of gliorosein.) Gliorosein (50 mg.) was rapidly and almost completely oxidized when it was chromatographed on a column of neutral alumina (Woelm) $(30 \mathrm{~g}$.$) , weakened to$ Brockmann grade II. The quinone was eluted as a yellow zone with ether-light petroleum $(1: 19, v / v)$ and crystallized. It had the same specific activity as the original gliorosein. Occasionally the quinone was also chromatographed on thin-layer plates of Kieselgel G (E. Merck A.-G., Darmstadt, Germany) with benzene-methanol $(99: 1, v / v)$ as eluting solvent. Ergosterol was isolated and purified as described by Packter (1965).

Chromatography. Details of adsorbents for column chromatography have been given previously (Packter, 1965).

Isolation of C-methyl groups (Kuhn-Roth oxidation). The isolation of $C$-methyl groups was carried out by the method of Barthel \& Laforge (1944). Gliorosein or quinone (50 mg.) was refluxed for $90 \mathrm{~min}$. with $5 \mathrm{ml}$. of chromic acid solution. Anhydrous $\mathrm{MgSO}_{4}$ (7g.) was then added to the reaction mixture and the acetic acid present was steam-distilled. The distillate (approx. $50 \mathrm{ml}$.) was titrated with $0.05 \mathrm{~N}-\mathrm{NaOH}$ and the sodium acetate thus produced was obtained as an amorphous solid after rotary evaporation. In the doublylabelled methionine experiment, the sodium acetate was acidified and purified by partition chromatography on Celite (Swim \& Utter, 1957). The acetic acid was titrated with $0.05 \mathrm{~N}-\mathrm{NaOH}$ to $\mathrm{pH} \mathrm{8.5-9.0}$ and assayed for radioactivity after freeze-drying.

Preparation of p-nitrobenzyl acetate. Occasionally the $p$-nitrobenzyl ester was prepared (Vogel, 1957). The reaction mixture was cooled and extracted with ether. The ether extract was chromatographed on silicic acid-Celite and unchanged $p$-nitrobenzyl bromide was eluted with ether-light petroleum $(1: 19, \mathrm{v} / \mathrm{v}) . p$-Nitrobenzyl acetate was eluted from the column with ether-light petroleum $(1: 9, \nabla / v)$. The acetate was purified by thin-layer chromatography on Kieselgel $G$ with benzene-methanol $(99: 1, v / v)$ as the solvent. It had $R_{F} \mathbf{0 \cdot 6 0}$. The ester was crystallized from methanol and from light petroleum at $4^{\circ}$. It had m.p. $78^{\circ}$ and $\lambda_{\max }$. in ethanol $264 \mathrm{~m} \mu\left(E_{1}^{1 \%} \mathrm{~cm}\right.$. 395) (Found: C, $55 \cdot 4 ; \mathrm{H}, 4 \cdot 5 ; \mathrm{N}, 7 \cdot 3$. Calc. for $\mathrm{C}_{9} \mathrm{H}_{9} \mathrm{NO}_{4}$ : $\mathrm{C}, 55 \cdot 4 ; \mathrm{H}, 4 \cdot 6$; $\mathrm{N}, 7 \cdot 2 \%$ ). The $p$-nitrobenzyl bromide had $\lambda_{\max }$. in ethanol $271 \mathrm{~m} \mu\left(E_{1}^{1 \%} \mathrm{~cm} .510\right)$. The infrared-absorption spectrum of the acetate ester showed large peaks at $1740 \mathrm{~cm}^{-1}(\mathrm{CO})$ and at $1240 \mathrm{~cm} .^{-1}(\mathrm{C}-\mathrm{O})$.

Degradation of the isolated acetic acid. In the methionine and formate incorporation experiments, the sodium acetate obtained from the Kuhn-Roth procedure was degraded by the Schmidt reaction, by the method of Phares (1951), to obtain separate values for the methyl 
and carboxyl groups. The latter was converted into $\mathrm{CO}_{2}$ during the reaction with $\mathrm{NaN}_{3}$ and counted as $\mathrm{BaCO}_{3}$. The methyl group gave methylamine sulphate, which was isolated as 5-methylamino-2,4-dinitrotoluene (Grout, Benn, Imaseki \& Geissman, 1966). The product was crystallized from ethanol to give small yellow needles. They had m.p. $169^{\circ}$ and $\lambda_{\max }$. in ethanol 268,343 and $400 \mathrm{~m} \mu\left(E_{1}^{1 \%} \mathrm{~cm} .575\right.$ at $343 \mathrm{~m} \mu$ ) (Found: C, 45.2; H, 4.5; N, 19.8. Calc. for $\mathrm{C}_{8} \mathrm{H}_{9} \mathrm{~N}_{3} \mathrm{O}_{4}: \mathrm{C}, 45 \cdot 5 ; \mathrm{H}, 4 \cdot 3 ; \mathrm{N}, 19 \cdot 6 \%$ ). The infraredabsorption spectrum of the derivative showed a peak at $3400 \mathrm{~cm} .^{-1}$ (NH).

Isolation of the 0-methyl groups. The radioactivity in the $O$-methyl groups of gliorosein was determined by conversion into methyl iodide by the Zeisel reaction. Gliorosein (40 mg.) was refluxed for $20 \mathrm{~min}$. with a solution of $\mathrm{HI}$ ( $5 \mathrm{ml}$. of $57 \%, \mathrm{v} / \mathrm{v}$ ) and red phosphorus (100 mg.). The apparatus was swept with $\mathrm{N}_{2}$ and the liberated methyl iodide was bubbled through water $(3 \mathrm{ml}$.) and trapped in acetone $(10 \mathrm{ml}$.), which was contained in a bubbler surrounded by a freezing mixture. Anhydrous trimethylamine $(1 \mathrm{ml}$.) was added and the resulting precipitate of quaternary ammonium iodide was obtained by centrifugation. It was washed with acetone and ether (yield 90-95\%) and crystallized from ethanol. The crystals $(10 \mathrm{mg}$.) were dissolved in water and a sample was counted for assay of radioactivity.

Alkaline demethylation of gliorosein. In addition to the determination of the $O$-methyl groups by the Zeisel reaction, alkaline demethylation of gliorosein was also performed (Packter \& Steward, 1967) to give 3-hydroxy-4-methoxy-6methyltoluquinone. The difference between the specific activities of the original gliorosein and the prepared monohydroxyquinone is a measure of the radioactivity in one $O$-methyl group.

Spectrophotometry. Ultraviolet-absorption measurements were carried out in ethanol in a Unicam SP. 800A recording spectrophotometer. All substances (except $\mathrm{BaCO}_{3}$ and tetramethylammonium iodide) were assayed spectrophotometrically. Infrared-absorption spectra were recorded by a Unicam SP. 200 instrument as a Nujol mull between $\mathrm{NaCl}$ cells.

Assay of radioactivity. Radioactivity was generally measured with a Nuclear-Chicago Corp. gas-flow counter at $20 \%$ efficiency (Packter, 1965). Samples were assayed for ${ }^{3} \mathrm{H}$ and ${ }^{14} \mathrm{C}$ content in a Beckman LS-200B liquid-scintilla-

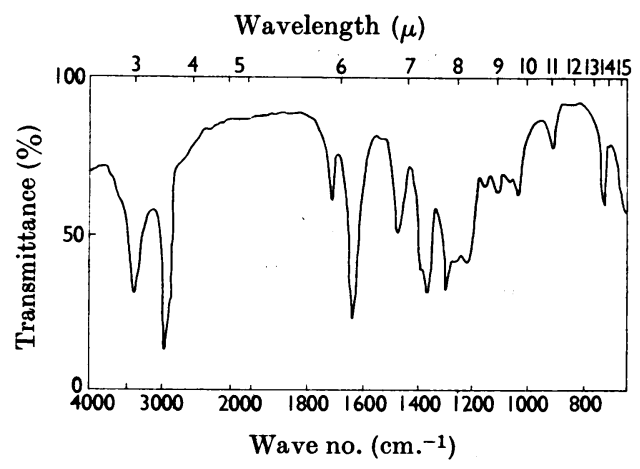

Fig. 1. Infrared-absorption spectrum of 3,4-dihydroxy-6methyltoluquinone (V). The spectrum was taken as a mull in Nujol. tion counter with dioxan containing naphthalene $(10 \%, w / v)$ and 2,5-diphenyloxazole $(0.5 \%, \mathrm{w} / \mathrm{v})$ as the scintillation fluid. Assays were performed in duplicate $0.1 \mathrm{ml}$. portions of water or ethanol containing $0.1 \mathrm{mg}$. of sample. Preliminary work established that no quenching of ${ }^{3} \mathrm{H}$ or ${ }^{14} \mathrm{C}$ occurred at this concentration except with tetramethylammonium iodide. In this instance $\mathrm{NaBH}_{4}$ was added to the scintillation fluid before addition of the sample to prevent the formation of a yellow colour (Bentley, Springer, Ramsey, Dialameh \& Olson, 1968). Radioactivity due to ${ }^{14} \mathrm{C}$ was confirmed in all cases in the gas-flow counter.

Melting points. These were determined in unsealed capillary tubes in a Gallenkamp melting-point apparatus and are uncorrected.

Analyses. C, $\mathrm{H}$ and $\mathrm{N}$ analyses were kindly performed by the Micro-analytical Laboratory, Department of Organic Chemistry, University of Leeds.

\section{MATERIALS}

Orcylaldehyde. This was prepared by subjecting anhydrous orcinol to a Gattermann reaction (Adams \& Levine, 1923). Anhydrous orcinol was prepared from the monohydrate after extraction of an aqueous solution with ether. The resulting extract was dried $\left(\mathrm{Na}_{2} \mathrm{SO}_{4}\right)$ and evaporated to dryness; the anhydrous material was crystallized from benzene. The orcylaldehyde thus produced was crystallized from boiling water and had m.p. 179-180 [Adams \& Levine (1923) gave m.p. 178-180 ${ }^{\circ}$ (Found: $\mathrm{C}, 63 \cdot 8 ; \mathrm{H}, 5 \cdot 2$. Calc. for $\mathrm{C}_{8} \mathrm{H}_{8} \mathrm{O}_{3}: \mathrm{C}, 63 \cdot 2 ; \mathrm{H}, 5 \cdot 3 \%$ ).

1,3-Dihydroxy-4,5-dimethylbenzene (II). Orcylaldehyde was converted into the dimethylresorcinol (II) by a Clemmenson reduction with zinc amalgam and $\mathrm{HCl}$ (Strating \& Backer, 1943). The product was chromatographed on silicic acid-Celite. It was eluted with ether-light petroleum $(3: 7, v / v)$ and crystallized from benzene or chloroform-light petroleum. It had m.p. 134-136 ${ }^{\circ}$ [Strating \& Backer (1943) found m.p. $135-137^{\circ}$ for the anhydrous material] and $\lambda_{\text {max. }}$ in ethanol $282 \mathrm{~m} \mu\left(E_{1}^{1 \%} \mathrm{~cm}\right.$. 170) (Found: $\mathrm{C}, 69 \cdot 3 ; \mathrm{H}, 7 \cdot 1$. Calc. for $\mathrm{C}_{8} \mathrm{H}_{10} \mathrm{O}_{2}$ : $\mathrm{C}, 69 \cdot 5 ; \mathrm{H}, 7 \cdot 3 \%$ ). After incubation with Raulin-Thom medium at $26^{\circ}$ for 5 days, $75 \%$ of the original phenol was recovered.

5-Methylorcylaldehyde (III). A second Gattermann reaction was carried out (as described above) on the dimethylresorcinol and resulted in the production of 5-methylorcylaldehyde. This was crystallized from boiling water. The pale-yellow needles $(80 \%$ yield) were chromatographed on silicic acid-Celite and were eluted with etherlight petroleum $(3: 17, v / v)$. They gave m.p. $194^{\circ}$ [Robertson \& Whalley $(1949)$ reported m.p. $\left.196^{\circ}\right]$ and $\lambda_{\max }$. in ethanol 292 and $335 \mathrm{~m} \mu\left(E_{1}^{1 \%} \mathrm{~cm} .805\right.$ and 320 respectively) (Found: C, 65.1; H, 5.9. Calc. for $\mathrm{C}_{9} \mathrm{H}_{10} \mathrm{O}_{3}: \mathrm{C}, 65 \cdot 0 ; \mathrm{H}, 6 \cdot 0 \%$ ).

5-Methylorsellinic acid (IV). 5-Methylorsellinic acid was obtained by the oxidation of 5-methylorcylaldehyde via a number of steps (Hoesch, 1913). It was crystallized from chloroform and had m.p. 161-163 ${ }^{\circ}$ [Robertson \& Whalley (1949) gave m.p. 162-163 ${ }^{\circ}$. It had $\lambda_{\max }$. in ethanol 264 and $307 \mathrm{~m} \mu\left(E_{1 \%}^{1 \%} 530\right.$ and 260 respectively) (Found: C, 59.1; $\mathrm{H}, 5 \cdot 6$. Calc. for $\mathrm{C}_{9} \mathrm{H}_{10} \mathrm{O}_{4}$ : C, 59.3; H, 5.5\%). Approx. $50 \%$ of the acid was recovered after incubation with Raulin-Thom medium at $26^{\circ}$ for 6 days, the remainder being decarboxylated to the corresponding phenol (II).

3,4 - Dihydroxy - 6 - methyltoluquinone (V). Gliorosein (100 mg.) was treated with $\mathrm{HI}(10 \mathrm{ml}$.) and red phosphorus 
(100 mg.) for $15 \mathrm{~min}$. under reflux. The reaction mixture was cooled, diluted with water and extracted with ether. The dihydroxyquinone (V) was chromatographed on silicic acid-Celite and eluted with ether-light petroleum $(7: 13$, $\nabla / v)$. It was rechromatographed and crystallized from ether. It had m.p. $195-200^{\circ}$ (decomp.) and $\lambda_{\max }$. in ethanol 272,279 and $470 \mathrm{~m} \mu\left(E_{1}^{1 \%}\right.$. 980,1020 and 90 respectively) (Found: $\mathrm{C}, 57 \cdot 4 ; \mathrm{H}, 4 \cdot 7 ; \mathrm{C}_{8} \mathrm{H}_{8} \mathrm{O}_{4}$ requires $\mathrm{C}, 57 \cdot 2 ; \mathrm{H}, 4.8 \%$ ). It gave an intense blue colour on the addition of alkali. The infrared-absorption spectrum of 3,4-dihydroxy-6methyltoluquinone has not been recorded previously and is shown in Fig. 1. It exhibited peaks at 1630, 1710 (quinone), 1220,1295 (phenolic $\mathrm{OH}$ deformation) and $3400(\mathrm{OH}) \mathrm{cm} .^{-1}$. It was unstable in Raulin-Thom medium; at least $50 \%$ decomposed within $5 \mathrm{hr}$. and none remained after $21 \mathrm{hr}$. Preparation of the corresponding quinol by reduction of the quinone with $\mathrm{Na}_{2} \mathrm{~S}_{2} \mathrm{O}_{4}$ was unsuccessful owing to the rapid reoxidation of the quinol.

Solvents. Light petroleum (b.p. 40-60 ), ether and ethanol for spectroscopy were purified as described by Packter (1965).

Radioactive compounds. Sodium $\left[{ }^{14} \mathrm{C}\right]$ formate, $\mathrm{Na}^{14} \mathrm{CN}$, $\left[M e \cdot{ }^{14} \mathrm{C}\right]$ methionine and $\left[M e-{ }^{3} \mathrm{H}\right]$ methionine were obtained from The Radiochemical Centre (Amersham, Bucks.). Over $96 \%$ of the radioactivity present in [Me-14C]methionine was located in the $S$-methyl group.

methyl-14C-labelled substrates were prepared as described above. [formyl $-{ }^{14} \mathrm{C}$ ] Orcylaldehyde was first formed by treatment of anhydrous orcinol with $\mathrm{Zn}(\mathrm{CN})_{2}$ and $\mathrm{Na}^{14} \mathrm{CN}$. The ${ }^{14} \mathrm{C}$-labelled compounds thus produced were purified to constant specific activity and melting point and moved as discrete zones in various chromatographic systems (Curtis, Harries, Hassall \& Levi, 1964). Other phenolic contaminants were not detected. This was confirmed by radioautography. Degradation of 1,3-dihydroxy-4[14C],5-dimethylbenzene and $5\left[{ }^{14} \mathrm{C}\right]$-methylorcylaldehyde confirmed that the radioactivity was distributed exclusively in the $C$-methyl groups.

ring- ${ }^{14} \mathrm{C}$-labelled orcylaldehyde was also prepared, since, if orcylaldehyde is a precursor of gliorosein, the labelled carbon atom from [ formyl-14C] orcylaldehyde would be lost by decarboxylation during the synthesis. $\left[{ }^{14} \mathrm{C}\right]$ Orcinol was first obtained from [ ${ }^{14} \mathrm{C}$ ]orsellinic acid as described by Birkinshaw \& Gowlland (1962). This was then subjected to a Gattermann reaction (Adams \& Levine, 1923).

\section{RESULTS}

Incorporation experiments with $5\left[{ }^{14} \mathrm{C}\right]-$ methylorsellinic acid and related compounds. The prepared ${ }^{14} \mathrm{C}$-labelled 'phenol' (1,3-dihydroxy-4,5-dimethylbenzene), $5\left[{ }^{14} \mathrm{C}\right]$-methylorcylaldehyde and $5\left[{ }^{14} \mathrm{C}\right]$ methylorsellinic acid were tested for possible activity as precursors of gliorosein in G. roseum. The results are shown in Table 1 . The ${ }^{14} \mathrm{C}$-labelled phenol was not incorporated into gliorosein and approx. $40 \%$ of the initial amount was recovered unchanged from the medium. Further, 5-methylorsellinic acid was not incorporated into gliorosein. It was decarboxylated to the corresponding phenol, which was recovered from the medium. However, $5\left[{ }^{14} \mathrm{C}\right]$-methylorcylaldehyde was effectively incorporated (36\% conversion) into gliorosein and related oxidation products. All the radioactivity in the gliorosein was present in the $C$-methyl groups (Table 2). In this latter group, no residual aldehyde, acid or phenol was detected in the medium.

Testing of ring-14C-labelled orcylaldehyde. This substrate was added to cultures of the organism after 10 days' growth and incubation continued for a further 5 days. Gliorosein was isolated from the medium and purified, but there was no incorporation of radioactivity into this product. No residual orcylaldehyde, orsellinic acid or orcinol (apart from possibly microgram traces) was present in the medium.

Conversion of ${ }^{14} \mathrm{C}$-labelled 3,4-dihydroxy-6-methyltoluquinone into gliorosein. This quinone was effectively incorporated into gliorosein $(15 \%)$ [and

\section{Table 1. Testing of activity of aromatic substrates as possible precursors for gliorosein biosynthesis}

The ${ }^{14} \mathrm{C}$-labelled substrates were prepared and purified as described in the text. They were added to two Roux bottles after 9 days' growth and incubation was continued for a further 7 days. Results are expressed as totals/ $400 \mathrm{ml}$. of medium.

\begin{tabular}{|c|c|c|c|c|c|c|}
\hline \multirow[b]{2}{*}{ Test substrate } & \multirow[b]{2}{*}{ Wt. (mg.) } & \multirow[b]{2}{*}{$\begin{array}{c}\text { Sp. activity } \\
\text { (counts/min./ } \\
\mu \text { mole) }\end{array}$} & \multirow[b]{2}{*}{$\begin{array}{l}\text { Wt. } \\
\text { recovered } \\
\text { (mg.) }\end{array}$} & \multicolumn{2}{|c|}{$\begin{array}{c}\text { Gliorosein and oxidation } \\
\text { products }\end{array}$} & \multirow[b]{2}{*}{$\begin{array}{c}\text { Incorporation } \\
(\%)\end{array}$} \\
\hline & & & & Wt. (mg.) & $\begin{array}{c}\text { Sp. activity } \\
\text { (counts/min./ } \\
\mu \mathrm{mole})\end{array}$ & \\
\hline $\begin{array}{l}\text { 1,3-Dihydroxy-4,5- } \\
\text { dimethylbenzene (II) }\end{array}$ & 40 & 620 & $15 \cdot 9$ & 165 & $\mathbf{0}$ & - \\
\hline 5-Methylorsellinic acid (IV) & 20 & 618 & $6 \cdot 4^{*}$ & 134 & $\mathbf{0}$ & - \\
\hline 5-Methylorcylaldehyde (III) & 40 & 650 & 0 & 240 & 43 & 36 \\
\hline Orcylaldehyde & 20 & 505 & $\mathbf{0}$ & 201 & $\mathbf{0}$ & - \\
\hline 3,4-Dihydroxy-6-methyl- & 18 & 1460 & $\mathbf{0}$ & 238 & 22 & 20 \\
\hline
\end{tabular}

* This was recovered as compound (II). 
quinhydrone (5\%)] (Table 1). The apparent low level of conversion, compared with the corresponding monomethoxy- and dimethoxy-quinone (30 and 57\% respectively) (Packter \& Steward, 1967), is due to the rapid rate of decomposition in the medium (see the Materials section).

\section{Table 2. Degradation of gliorosein derived from $5\left[{ }^{14} \mathrm{C}\right]-$ methylorcylaldehyde}

Gliorosein was oxidized to the corresponding quinone and degraded by the Kuhn-Roth procedure to yield the $C$-methyl groups as sodium acetate. 5-Methylorcylaldehyde was similarly degraded. The sodium acetate was purified as the $p$-nitrobenzyl ester (see the Methods section) and estimated spectrophotometrically.

$\begin{array}{ccc}\text { Sp. activity } & \begin{array}{c}p \text {-nitrobenzyl } \\ \text { acetate } \\ \text { (counts/min./ } \\ \text { (counts/min./ } \\ \mu \text { mole) }\end{array} \\ \begin{array}{c}\text { Substrate } \\ \begin{array}{c}{ }^{14} \text { C]-Methyl- } \\ \text { orcylaldehyde }\end{array}\end{array} & 650 & 620 \\ \text { Gliorosein } & 43 & 44\end{array}$

Incorporation of $\left[\mathrm{Me}-{ }^{14} \mathrm{C}\right]$ methionine and sodium $\left.{ }^{14} \mathrm{C}\right]$ formate. [Me-14 $\left.\mathrm{C}\right]$ Methionine was effectively incorporated into gliorosein and related metabolites when added to the culture medium after 6 and 10 days' growth (6.2 and $22 \cdot 2 \%$ respectively). Sodium [ $\left.{ }^{14} \mathrm{C}\right]$ formate, added after 10 days' growth, was similarly incorporated $(15.4 \%$ conversion) into gliorosein and products. The results are presented in Tables 3 and 4. Some quinol and quinhydrone were also present; their specific activity was identical (within 5\%) with that of gliorosein. The degradation of gliorosein is given in Scheme 1.

Since the gliorosein molecule is symmetrical and one of the $C$-methyl groups arises from acetate, the true value for the specific activity of the $C$-methyl group is double the experimental value and is recorded as such. Isolation and estimation of the radioactivity in the $O$-methyl and $C$-methyl groups of the gliorosein from the three experiments showed an appreciable difference in the specific activities of the two types of methyl group (35, 14 and $15 \%$ in the three groups respectively). All the radioactivity in the original gliorosein was recovered in the $O$-methyl and $C$-methyl groups. Experience

Table 3. Incorporation of $\left[M e^{-14} \mathrm{C}\right]$ methionine and sodium $\left[{ }^{14} \mathrm{C}\right]$ formate into gliorosein

Each group consisted of two Roux bottles. [Me. ${ }^{14} \mathrm{C}$ ]Methionine $(50 \mu \mathrm{C})$ and sodium [14 C]formate $(100 \mu \mathrm{C})$ were added at the times indicated. Incubation was continued for a total of 15 days from inoculation. The results are expressed as totals $/ 400 \mathrm{ml}$. of medium.

\begin{tabular}{|c|c|c|c|c|}
\hline \multirow[b]{2}{*}{ Substrate } & \multirow[b]{2}{*}{$\begin{array}{c}\text { Time of addition } \\
\text { (days) }\end{array}$} & \multicolumn{2}{|c|}{ Gliorosein } & \multirow{2}{*}{$\begin{array}{c}\text { Incorporation into } \\
\text { gliorosein and related } \\
\text { products } \\
(\%)\end{array}$} \\
\hline & & Wt. (mg.) & $\begin{array}{c}\text { Sp. activity } \\
\text { (counts } / \mathrm{min} . / \mu \text { mole) }\end{array}$ & \\
\hline Methionine (Expt. I) & 6 & 262 & 815 & $6 \cdot 2$ \\
\hline Methionine (Expt. II) & 10 & 420 & 2100 & $22 \cdot 2$ \\
\hline Formate & 10 & 130 & 5650 & $15 \cdot 4$ \\
\hline
\end{tabular}

Table 4. Degradation of gliorosein derived from $\left[M e-{ }^{14} \mathrm{C}\right]$ methionine and sodium $\left[{ }^{14} \mathrm{C}\right]$ formate

Gliorosein was degraded to obtain values for the activities of the $O$-methyl and $C$-methyl groups as described in Scheme 1. Experimental details are given in Table 3.

\begin{tabular}{|c|c|c|c|c|c|}
\hline \multirow[b]{2}{*}{ Substrate } & \multirow[b]{2}{*}{... } & \multirow[b]{2}{*}{$\cdots$} & \multicolumn{3}{|c|}{ Sp. activity (counts $/ \mathrm{min} . / \mu$ mole) } \\
\hline & & & $\begin{array}{l}\text { Methionine } \\
\text { (Expt. I) }\end{array}$ & $\begin{array}{l}\text { Methionine } \\
\text { (Expt. II) }\end{array}$ & Formate \\
\hline & & & 815 & 2100 & 5650 \\
\hline
\end{tabular}

Gliorosein (C-1-C-10)

815

1370

(a) Total as ester (C-1, C-6, C-7 and C-8)

$\begin{array}{lll}195 & - & 1370 \\ - & 650 & 1625\end{array}$

(c) $\mathrm{C}-1$ and $\mathrm{C}-6$ as $\mathrm{BaCO}_{3}$

$O-\mathrm{CH}_{3}$ group (C-9 and $\mathrm{C}-10$ )

(a) $\mathrm{As}\left(\mathrm{CH}_{3}\right)_{4} \mathrm{NI}$

(b) Calculated*

$\mathrm{C} \cdot \mathrm{CH}_{3}+2 \times O \cdot \mathrm{CH}_{3}$ (average)

$\%$ difference between

$\mathrm{C} \cdot \mathrm{CH}_{3}$ and $\mathrm{O} \cdot \mathrm{CH}_{3}$

$\begin{array}{rrr}- & 650 & 1625 \\ - & 0 & 12 \\ 316 & 790 & 1845 \\ 280 & 726 & 1960 \\ 791 & 2166 & 5430 \\ 35 & 14 & 15\end{array}$

* Calculated by difference from the specific activity of gliorosein and 3-hydroxy-4-methoxy-6-methyltoluquinone, 


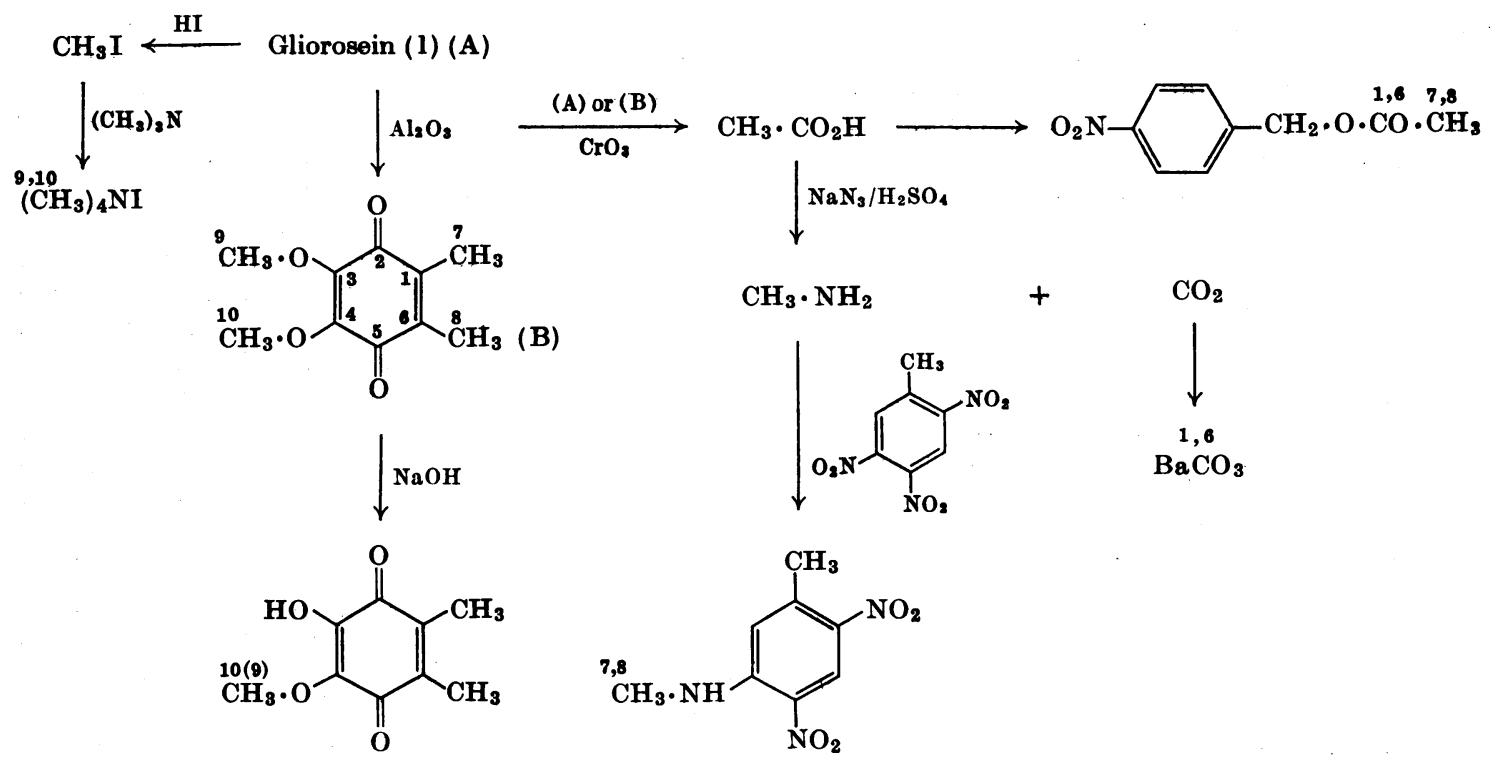

Scheme 1. Degradation of gliorosein.

Table 5. ${ }^{14} \mathrm{C} /{ }^{3} \mathrm{H}$ ratio in ergosterol, gliorosein and degradation products

Experimental details are given in the Methods section.

\begin{tabular}{lccc} 
& & \multicolumn{2}{c}{${ }^{14} \mathrm{C} /{ }^{3} \mathrm{H}$ atomic ratio } \\
\cline { 3 - 4 } Methionine & Observed ${ }^{14} \mathrm{C} /{ }^{3} \mathrm{H}$ ratio & Corrected & Expected \\
$O \cdot \mathrm{CH}_{3}$ of gliorosein & $1: 4 \cdot 83 \pm 0 \cdot 03(5)$ & $1: 3 \cdot 00$ & $1: 3$ \\
$C \cdot \mathrm{CH}_{3}$ of gliorosein & $1: 4 \cdot 92 \pm 0 \cdot 12(8)$ & $1: 3 \cdot 06$ & $1: 3$ \\
Ergosterol & $1: 3 \cdot 48 \pm 0 \cdot 08(8)$ & $1: 2 \cdot 16$ & $1: 2$ (or $1: 3)$ \\
Gliorosein & $1: 3 \cdot 38 \pm 0 \cdot 03(8)$ & $1: 2 \cdot 09$ & $1: 2$ \\
3-Hydroxy-4-methoxy-6-methyltoluquinone & $1: 4 \cdot 31 \pm 0 \cdot 05(8)$ & $1: 2 \cdot 70$ & $1: 2 \cdot 67$ (or $1: 3)$ \\
& $1: 4 \cdot 17 \pm 0 \cdot 03(4)$ & $1: 2 \cdot 57$ & $1: 2 \cdot 5$ (or $1: 3$ )
\end{tabular}

showed that purification of $p$-nitrobenzyl acetate was difficult when small amounts were available. Thus the discrepancy in the specific activity of the acetate ester and the methylamine derivative in the $\left.{ }^{14} \mathrm{C}\right]$ formate group is probably due to the presence of some unchanged $p$-nitrobenzyl bromide in the preparation. Accordingly, the value for the methylamine derivative, when available, was taken as the correct one. The value for one $O$-methyl group was confirmed by the difference in specific activities of gliorosein and the monohydroxyquinone.

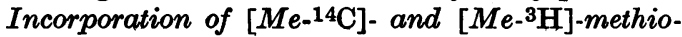
nine into metabolites of G. roseum. A mixture of these labelled substrates (20 $\mu \mathrm{C}$ and $400 \mu \mathrm{C}$ respectively) was added to each of three Roux bottles after 10 days' growth. Ergosterol (28 mg.; specific activity 14180 counts $/ \mathrm{min} . / \mu \mathrm{mole}$ ) and gliorosein (293 mg.; speciflo activity 7050 counts/min./ $/ \mathrm{mole}$ ) were isolated 4 days later from the mycelium and medium respectively. Incorporation into gliorosein was $25 \%$ on the basis of ${ }^{14} \mathrm{C}$. Gliorosein was converted into the quinone and degraded to give tetramethylammonium iodide (specific activity 2405 counts $/ \mathrm{min} . / \mu \mathrm{mole}$ ) and sodium acetate (specific activity 1705 counts $/ \mathrm{min} . / \mu \mathrm{mole}$ ) (see the Methods section). Again, the specific activity of the $O$-methyl group was considerably higher than that found for the $C$-methyl group $(29 \%)$. The ratios of the radioactivity due to ${ }^{14} \mathrm{C}$ and ${ }^{3} \mathrm{H}$ are given in Table 5. The ${ }^{14} \mathrm{C} /{ }^{3} \mathrm{H}$ ratio in the tetramethylammonium iodide was the same as that of the original methionine mixture, whereas the ratio for the sodium acetate was much higher and similar to that determined for ergosterol, indicating that the two methylation reactions occurred via different meohanisms. 


\section{DISCUSSION}

It has been established in a number of Laboratories that acetate and malonate (presumably via their CoA derivatives) are converted directly into an aromatic precursor of gliorosein. We have previously suggested that 5-methylorsellinic acid, and not orsellinic acid or 6-methylsalicylic acid, is the primary aromatic compound involved (Packter \& Steward, 1967). Indeed, the results obtained in this work (Tables 1 and 2 ) clearly show that $5\left[{ }^{14} \mathrm{C}\right]$ methylorcylaldehyde (III) is readily converted into gliorosein. However, the related resorcinol ('phenol') (II) and acid (IV) are not incorporated. These results may be explained by suggesting that 5 -methylorsellinic acid is actually formed in vivo by $G$. roseum as an enzyme-bound intermediate of the type R.CO.S.Enzyme. Presumably, when 5methylorsellinic acid is added to growing cultures of $G$. roseum, it cannot be converted into this enzyme-bound derivative since it is rapidly decarboxylated by a decarboxylase present in the mycelium (J. S. Collins \& N. M. Packter, unpublished work). 5-Methylorcylaldehyde may, however, react with a thiol group of the enzyme, followed by dehydrogenation, to produce the necessary acyl thiol ester, which could then be incorporated into gliorosein. The complex produced in this way would be hydroxylated at C-3 before hydrolysis to give the trihydroxy compound. If hydrolysis occurred before hydroxylation, the acid thus produced would be decarboxylated to give the phenol (II). This is unlikely since it has been shown that this substance is not incorporated into gliorosein. Moreover, no phenol was detected in the medium after it had been supplemented with 5-methylorcylaldehyde. Hydrolysis of the thiol ester group, decarboxylation, further hydroxylation and $O$-methylation of the hydroxyl groups, para to the methyl groups, would give 3,4-dimethoxy-6methyltoluquinol. This may then be converted into gliorosein by a tautomerase enzyme. Evidence for the existence of this enzyme has been obtained from whole cells (Packter \& Steward, 1967) and cell-free extracts of the organism (M. W. Steward \& N. M. Packter, unpublished work).

The inactivity of orcylaldehyde as a precursor of gliorosein further supports the hypothesis that the additional $C$-methyl group is added at the aliphatic level. Presumably, even if the required enzymebound derivative of this aldehyde were formed, methylation of the aromatic ring at C-5 to produce the 5-methyl derivative cannot occur.

The results of the methionine and formate incorporation experiments reveal a significant difference in the labelling of the $O$-methyl and $C$-methyl groups of gliorosein from both substrates. They confirm the pattern observed by Birch et al. (1958b). The results from the formate experiment also preclude the incorporation of the $C_{1}$ unit into the $C$-methyl group via a tetrahydrofolate derivative. If this had occurred, the $O$-methyl groups that arise from $S$-adenosylmethionine (Greenberg, 1963 ) would have had a lower specific activity.

The addition of $\left[\mathrm{Me}-{ }^{14} \mathrm{C}\right]$ methionine to cultures of $G$. roseum after 6 and 10 days' growth resulted in a very marked difference in the incorporation of label into gliorosein and related metabolites $(6 \cdot 2$ and $22.2 \%$ respectively) (Table 3 ). At 6 days, growth and protein synthesis would be proceeding rapidly. The added $\left[\mathrm{Me}-{ }^{14} \mathrm{C}\right]$ methionine might be expected to be incorporated into protein, phospholipid and ergosterol, leaving less available for gliorosein synthesis. After 10 days, however, growth (formation of mycelium) would be nearly complete, probably leaving more labelled methionine for synthesis of gliorosein. A similar situation was noted with the incorporation of [2-14C] acetate into fumigatol in Aspergillus fumigatus (Packter \& Glover, 1965). Incorporation was very low at early stages of growth. Further, Packter \& Steward (1967) have shown that the incorporation of $\left[2 .{ }^{14} \mathrm{C}\right]$ acetate into ergosterol tends to decrease with time.

The ${ }^{14} \mathrm{C} /{ }^{3} \mathrm{H}$ ratios given in Table 5 clearly indicate that two tritium atoms from the original methyl group of methionine are transferred during the $C$-methylation to a precursor of gliorosein. Jauréguiberry, Law, McCloskey \& Lederer (1965) have previously established that only two deuterium atoms from $\left[\mathrm{Me}^{2}{ }^{2} \mathrm{H}_{3}\right]$ methionine are incorporated into ergosterol in Neurospora crassa. These workers have also shown that tuberculostearic acid is formed in a similar manner in Mycobacterium smegmatis. It was initially thought that $C$-methylation during the synthesis of these substances might occur via an ylide derivative of $S$-adenosylmethionine, in which a proton had been lost before the transfer reaction (Pohl et al. 1963; Lederer, 1964). More recently, Akhtar et al. (1967) have suggested that in ergosterol biosynthesis the entire methyl group may be transferred to the ethylenic group in the side chain of lanosterol. A 1,2-hydride transfer could then occur with loss of one of the hydrogen atoms of the methyl group to give 24-methylenelanosterol. However, these results do not preclude the formation of this product by a methylene-transfer mechanism. But if $C$-methylation does indeed parallel $O$-, $N$ - and $S$-methylation, in that the methyl group is initially transferred intact (rather than after prior conversion into a methylene derivative), some explanation for the higher specific activity of the $O$-methyl groups of gliorosein (Table 4) must be given. One possibility is that two methyl group pools are involved. The polyketide may be methylated by a $C$-methylase within an 'aromatic acid 
synthetase' enzyme complex. The final product of this series of reactions would be 1,2,3-trihydroxy4,5-dimethylbenzene (or the 1,2,3,4-tetrahydroxy compound). This might then be released to another part of the cell, e.g. the cell membrane, where it is $O$-methylated before tautomerization intogliorosein. Alternatively, if there had been a considerable amount of $C$-methylated precursor present in the mycelium at the time of addition of labelled substrate, the $O$-methyl groups formed subsequently would have a higher specific activity.

Direct $\boldsymbol{C}$-methylation of an aromatic ring does not appear to be involved in gliorosein biosynthesis, but it has been established in other instances. $p$-Hydroxybenzaldehyde and $p$-hydroxybenzoic acid are precursors of ubiquinone in microorganisms and animal tissues (Parson \& Rudney, 1965; Burton \& Glover, 1965). The conversion of these compounds into ubiquinone therefore requires $C$-methylation of an aromatic precursor. Threlfall, Whistance \& Goodwin $(1967,1968)$ have shown, using $\left[\mathrm{Me}-{ }^{14} \mathrm{C}\right]$ - and $\left[\mathrm{Me}^{-3} \mathrm{H}\right]$-methionine, that both the $O$-methyl and the $C$-methyl groups arise by the transfer of intact methyl groups. The ${ }^{14} \mathrm{C} /{ }^{3} \mathrm{H}$ ratio is retained as $1: 3$. Further, Jauréguiberry, Lenfant, Das \& Lederer (1966) have shown that all three deuterium atoms from $\left[\mathrm{Me}-{ }^{2} \mathrm{H}_{3}\right]$ methionine are recovered in the $C$-methyl group of dihydromenaquinone-9 in $M$. smegmatis. Transfer of a methyl group (without subsequent loss of deuterium) to the phenolic hydroxyl group and aromatic carbon atom of mycophenolic acid (Birch, English, Massy-Westropp, Slaytor \& Smith, 1958a) has also been demonstrated by using $\left[\mathrm{Me}^{2} \mathrm{H}_{3}\right]$ methionine (Jauréguiberry, Farrugia-Fougerouse, Audier \& Lederer, 1964). Presumably, therefore, this $C$ methyl group is also added at the aromatic level (cf. Table 5).

The results expressed in this paper, we believe, present the first direct experimental proof that certain $C$-methylation reactions occur at the polyketide level. However, several investigators have provided indirect evidence in support of this suggestion (for references see Packter \& Steward, 1967). In addition, Yamazaki, Matsuo \& Shibata (1965) have shown that $[1.14 \mathrm{C}]$ acetate is incorporated into lecanoric acid (VI) (a depside derived from $2 \mathrm{~mol}$. of orsellinic acid) by the lichen Parmelia tinctorum. However, Yamazaki \& Shibata (1966) have shown that $\left[{ }^{14} \mathrm{C}\right]$ orsellinic acid is converted into lecanoric acid, but not into the related atranorin (VII), which possesses an additional $\mathrm{C}_{1}$ unit on each ring. Thus incorporation of the $C_{1}$ units during the formation of this depside presumably also occurs at the polyketide stage before aromatization.

Pettersson (1965), however, has stated that both orsellinic acid and 5-methylorsellinic acid are incorporated in very low yield into the quinone derivative of gliorosein ( 0.07 and $0.9 \%$ respectively). The acids were converted mainly into their decarboxylation products. He inferred that orsellinic acid itself was therefore $C$-methylated. (No gliorosein was detected in this work.) In view of the limited purification (crystallization from one solvent) and low incorporation, it is possible that this radioactivity was due to the presence of a contaminant.

From the results described in this paper and by Lynen \& Tada (1961), a suggested pathway for gliorosein biosynthesis may be proposed (Scheme 2). The first stage would be the condensation of acetyl-CoA and 3 malonyl-CoA units to produce a polyketomethylene chain (Lynen \& Tada, 1961). This is presumably stabilized after enolization by bonding to thiol groups etc. on an enzyme complex (Sjöland \& Gatenbeck, 1966). Methylation of a resulting methine carbon atom with $S$-adenosylmethionine occurs at some stage, followed by cyclization; this results in the formation of the primary phenolic precursor, an enzyme-bound form of 5-methylorsellinic acid. This type of intermediate also occurs in fatty acid biosynthesis (Wakil, Pugh \& Sauer, 1964; Lynen, 1967). The condensation, methylation and cyclization reactions may possibly be catalysed by an enzyme complex similar to that involved in fatty acid synthesis (Lynen, 1967) and that suggested for alternariol biosynthesis (Sjöland \& Gatenbeck, 1966). The 5-methylorsellinyl-enzyme derivative is then converted into gliorosein as described above.

Now, why does G. roseum secrete gliorosein into the medium? Indeed, a similar question may be asked of all fungi (and bacteria) that produce 'secondary' metabolites. Excessive production of these substances by fungi under laboratory conditions is probably related to the high concentration<smiles>Cc1cc(OC(=O)c2c(C)cc(O)cc2O)cc(O)c1C(=O)O</smiles>

(VI)<smiles>CC(=O)c1c(C)cc(OC(=O)c2c(C)cc(O)c(C=O)c2O)c(C)c1O</smiles>

(VII) 


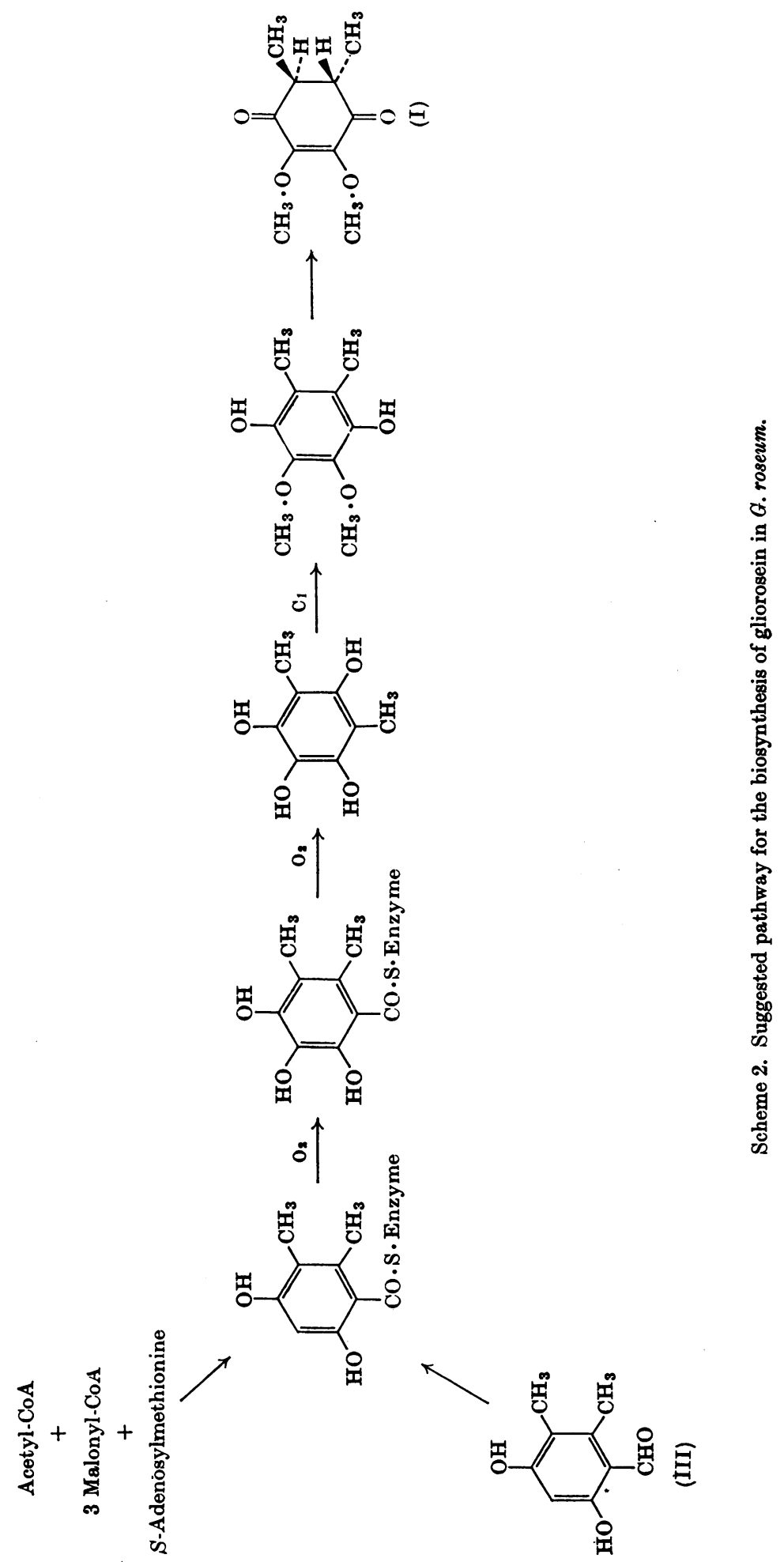


of carbohydrate in the medium. This results in the production of excess of acetyl-CoA and tricarboxylic acid-cycle intermediates, which could give rise to allosteric activation of secondary biosynthetic enzymes, especially when the supply of nitrogen or phosphorus or other essential components becomes limiting. Their production in the natural environment may be caused by internal factors such as the build-up of primary metabolites after balanced growth has ceased (Bu'Lock, 1965). G. roseum, for example, can convert acetyl-CoA into a readily excretable substance, gliorosein (Scheme 2). By this elaborate means, the balance in the internal environment of the cell would be restored, e.g. by releasing CoA (compare the production of ketone bodies from acetyl-CoA in diabetes). It is self-evident that $G$. roseum (and other organisms that utilize secondary pathways) possesses the genetic capacity to produce the enzymes required. If these secondary processes do occur in the soil (and this has not been shown), the considerable intrinsic energy of the products would not be lost to Nature, but could be utilized by bacteria that are present (Dagley, Evans \& Ribbons, 1960; Dagley, 1965).

Brock \& Bloch (1966) have shown that acetyl-CoA may be converted into triacetic acid lactone (4-hydroxy-6-methyl-2-pyrone) by a crude fatty acid synthetase in $E$. coli. Presumably, therefore, a specific condensing enzyme (catalysing the reaction of a malonyl group with a $\beta$-oxo acid derivative) is present. When certain thiol reagents are added, synthesis of long-chain fatty acids is suppressed (even in the presence of NADPH) and replaced by the formation of triacetic acid lactone. The lactone is probably produced spontaneously from the corresponding acid (3,5-dioxohexanoic acid). Glucose 6-phosphate reverses this effect. Moreover, triacetic acid lactone is normally produced by this system at a basal level of approx. $10 \%$ compared with that of fatty acids. Thus this condensing enzyme is constitutive to $E$. coli and is associated with (but not necessarily part of) the fatty acid synthetase.

A similar mechanism, based on allosteric activation or inhibition of key enzymes, may be proposed for the formation of gliorosein (and other secondary metabolites) derived from products of condensation of acetyl and malonyl units in fungi.

M. W.S. acknowledges the support of a Science Research Council Research Studentship.

\section{REFERENCES}

Adams, R. \& Levine, I. (1923). J. Amer. chem. Soc. 45, 2373.

Akhtar, M., Hunt, P. F. \& Parvez, M. A. (1967). Biochem. J. $108,616$.
Anslow, W. K. \& Raistrick, H. (1938). Biochem. J. 32, 687.

Barthel, W. F. \& Laforge, F. B. (1944). Industr. Engng Chem. (Anal.), 16, 434.

Bentley, R. \& Lavate, W. V. (1965). J. biol. Chem. 240, 532.

Bentley, R., Springer, C. M., Ramsey, V. G., Dialameh, G. H. \& Olson, R. E. (1968). J. biol. Chem. 243, 174.

Birch, A. J., Cameron, D. W., Holloway, P. W. \& Rickards, R. W. (1960). Tetrahedron Lett. no. 25, p. 26.

Birch, A. J., English, R. J., Massy-Westropp, R. A., Slaytor, M. \& Smith, H. (1958a). J. chem. Soc. p. 365.

Birch, A. J., Fryer, R. I. \& Smith, H. (1958b). Proc. chem. Soc., Lond., p. 343.

Birkinshaw, J. H. \& Gowlland, A. (1962). Biochem. J. 84, 342.

Brock, D. J. H. \& Bloch, K. (1966). Biochem. biophys. Res. Commun. 23, 775.

Bu'Lock, J. D. (1965). In Biosynthesis of Natural Products, p. 9. London: McGraw-Hill Book Co.

Burton, D. N. \& Glover, J. (1965). Biochem. J. 94, 27 P.

Curtis, R. F., Harries, P. C., Hassall, C. H. \& Levi, J. D. (1964). Biochem. J. 90, 43.

Dagley, S. (1965). Sci. Progr. 53, 381.

Dagley, S., Evans, W. C. \& Ribbons, D. W. (1960). Nature, Lond., 188, 560.

Greenberg, D. M. (1963). Advanc. Enzymol. 25, 395.

Grout, D. H. G., Benn, M. H., Imaseki, H. \& Geissman, T. A. (1966). Phytochemistry, 5, 1.

Hoesch, K. (1913). Ber. dtsch. chem. Ges. 46, 886.

Jauréguiberry, G., Farrugia-Fougerouse, G., Audier, H. \& Lederer, E. (1964). C. R. Acad. Sci., Paris, 259, 3108.

Jauréguiberry, G., Law, J. H., McCloskey, J. A. \& Lederer, E. (1965). Biochemistry, 4, 347.

Jauréguiberry, G., Lenfant, M., Das, B. C. \& Lederer, E. (1966). Tetrahedron, 1 (Suppl. 8), 27.

Lederer, E. (1964). Biochem. J. 93, 449.

Lynen, F. (1967). Biochem. J. 102, 381.

Lynen, F. \& Tada, M. (1961). Angew. Chem. 73, 513.

Packter, N. M. (1965). Biochem. J. 97, 321.

Packter, N. M. \& Glover, J. (1965). Biochim. biophys. Acta, 100, 50.

Packter, N. M. \& Steward, M. W. (1967). Biochem. J. 102 , 122.

Parson, W. W. \& Rudney, H. (1965). J. biol. Chem. 240, 1855.

Pastore, E. J. \& Friedkin, M. (1962). J. biol. Chem. 237, 3802.

Pettersson, G. (1965). Acta chem. scand. 19, 1827.

Phares, E. F. (1951). Arch. Biochem. Biophys. 33, 173.

Pohl, S., Law, J. H. \& Ryhage, R. (1963). Biochim. biophys. Acta, 70, 583.

Robertson, A. \& Whalley, W. B. (1949). J. chem. Soc. p. 3038.

Sjöland, S. \& Gatenbeck, S. (1966). Acta chem. scand. 20, 1053.

Steward, M. W. \& Packter, N. M. (1965). Biochem. J. 95, 26c.

Steward, M. W. \& Packter, N. M. (1967). Biochem. J. 103, 9 P. 
Strating, J. \& Backer, H. J. (1943). Rec. Trav. chim. Vogel, A. I. (1957). In Practical Organic Chemistry, p. 362. Pays-Bas, 62, 57.

Swim, H. E. \& Utter, M. F. (1957). In Methods in Enzymology, vol. 4, p. 584. Ed. by Colowick, S. P. \& Kaplan, N. O. New York and London: Academic Press Inc.

London: Longmans, Green and Co. Ltd.

Wahba, A. J. \& Friedkin, M. (1962). J. biol. Chem. 237, 3794.

Wakil, S. J., Pugh, E. L. \& Sauer, F. (1964). Proc. nat. Acad. Sci., Wash., 52, 106.

Threlfall, D. R., Whistance, G. R. \& Goodwin, T. W. (1967). Biochem. J. 102, 49 P.

Yamazaki, M., Matsuo, M. \& Shibata, S. (1965). Chem. Pharm. Bull., Tokyo, 13, 1015.

Threlfall, D. R., Whistance, G. R. \& Goodwin, T. W. Yamazaki, M. \& Shibata, S. (1966). Chem. Pharm. Bull., (1968). Biochem.J. 106, 107. Tokyo, 14, 96. 